\title{
Korelasi Faktor Fisika Kimia Perairan terhadap Densitas Belangkas di Pantai Timur Sumatera Utara
}

\author{
Correlation Factor of Chemical Physical Waters against the Density on Horseshoe Crab in East \\ Coast of North Sumatra
}

\author{
Khairul $^{1 *)}$, Zunaidy Abdullah Siregar ${ }^{2)}$, Rusdi Machrizal ${ }^{3)}$ \\ ${ }^{1,2,3)}$ STKIP Labuhan Batu, Pendidikan Biologi \\ *email: khairul_spi@yahoo.com
}

Received: 01/02/2019; Revised: 11/06/2019; Accepted: 11/06/2019

\begin{abstract}
Abstrak
Belangkas merupakan hewan yang dilindungi oleh Pemerintah Indonesia. Keberadaanya di alam sudah semakin jarang ditemukan. Banyak faktor yang diduga menjadi penyebab menurunnya densitas belangkas di habitatnya. Salah satu penyebabnya karena menurunnya kualitas air yang diakibatkan pencemaran perairan. Kondisi fisika kimia perairan merupakan faktor pembatas bagi belangkas. Kualitas air tentunya mencakup faktor fisika kimia, dimana harus sesuai dengan baku mutu dipersyaratkan. Tujuan penelitian adalah untuk mengetahui kondisi faktor fiisika kimia perairan dan korelasinya terhadap densitas belangkas di Pantai Timur Sumatera Utara. Penelitian ini merupakan penelitian eksploratif, dimana penentuan titik stasiun pengamatan menggunakan purposive sampling. Hasil penelitian menunjukan korelasi faktor fisika kimia perairan terhadap densitas belangkas di Pantai Timur Sumatera Utara mempunyai hubungan yang positif (+). Nilai korelasi tertinggi diperoleh pada suhu $(0,936)$, kecerahan $(0,702)$, salinitas $(0,603), \mathrm{Hg}(0,578), \mathrm{Cd}$ $(0,545), \mathrm{Pb}(0,508), \mathrm{pH}(0.405)$, kecepatan arus $(0,148)$, dan DO $(0,045)$.
\end{abstract}

Kata kunci: belangkas, faktor fisika kimia, korelasi, Sumatera Utara

\begin{abstract}
The horseshoe crab is protected animals by the Government of Indonesian. Occurrence in nature is getting rare. Many factors are suspected to be the cause of the decrease in the density of the horseshoe crab's habitat. One of the reasons because of declining water quality due to pollution of the waters. The condition of the aquatic chemical physical is a limiting factor for the horseshoe crab. Water quality is of course includes physical-chemical factors, which should correspond to the raw quality required. The purpose of the research is to find out the condition of the aquatic chemical physical factors and correlation against the density of horseshoe crab on the east coast of North Sumatera. This research is exploratory research, where the determination of the point of observation stations using purposive sampling. Results of the study showed a correlation factor of chemical physical waters against the density of horseshoe crab on the East coast of North Sumatra had a relationship that is positive $(+)$. The highest correlation value is obtained at a temperature of (0.936), brightness (0.702), salinity (0.603), $\mathrm{Hg}$ (0.578), $\mathrm{Cd}$ (0.545), $\mathrm{Pb}$ (0.508), $\mathrm{pH}(0.405)$, speed of the current (0.148), and DO (0.045).
\end{abstract}

Keywords: correlation, factor of chemical physics, horseshoe crab, North Sumatera 


\section{PENDAHULUAN}

Belangkas merupakan salah satu satwa dilindungi berdasarkan Surat Keputusan Menteri Kehutanan No. 12/ KPS -II/ 1987 dan Peraturan Pemerintah Nomor 7 tahun 1999. Kondisi belangkas saat ini terus mengalami penurunan populasi di alam. Menurut Ubaidillah $d k k$. (2013) dan Mulya (2004) belangkas sebagai hewan yang sudah kategori rawan atau jarang ditemukan.

Menurut Cartwright-Taylor $d k k$. (2011) salah satu jenis belangkas yakni Carcinoscorpius rotundicauda yang terdapat di India, Hongkong dan Singapora kini berada dalam kondisi yang mengkhawatirkan karena telah terjadinya penurunan populasi yang cukup signifikan. Bahkan jenis Limulus polyphemus sudah masuk dalam daftar status rentan (Vulnerable) (Smith $d k k ., 2016$ ).

Diduga salah satu faktor penyebab menurunnya jumlah populasi belangkas di alam adalah karena menurunnya kualitas perairan yang diakibatkan karena adanya pencemaran. Parameter kualitas air meliputi faktor fisika kimia yang merupakan faktor pembatas (limiting factor), sangat dibutuhkan oleh biota akuatik dimana tempat mereka hidup, salah satunya adalah belangkas.

Penelitian terbaru tentang belangkas dalam 10 tahun terakhir yang termuat di dalam artikel maupun tesis antara lain: Taylor dkk. (2011); Meilana (2015); Razali \& Zaleha (2017); Mashar dkk. (2017); Fan $d k k$. (2017); Anggraini $d k k$. (2017). Namun, belum ada laporan penelitian mengkaji tentang kondisi faktor fisika dan kimia perairan dan korelasinya terhadap densitas belangkas di Pantai Timur Sumatera Utara. Tujuan penelitian ini adalah untuk mengetahui kondisi faktor fisika kimia perairan dan hubungannya terhadap kepadatan populasi belangkas di perairan Pantai Timur Sumatera Utara.

\section{METODE PENELITIAN}

Penelitian ini merupakan penelitian eksploratif, yakni melakukan penelusuran dalam pemantapan konsep yang akan digunakan dalam ruang lingkup penelitian yang lebih luas dengan jangkauan konseptual yang lebih besar (Yusuf, 2017).

Penentuan titik stasiun pengamatan menggunakan metode purposive sampling. Metode purposive sampling ini dilakukan berdasarkan karakteristik habitat berbeda, dimana masih ditemukan belangkas. Stasiun pengamatan tersebut dijadikan tempat pengambilan sampel air dan sampel belangkas. Ketiga stasiun pengamatan, yakni: Stasiun 1 di wilayah kawasan hutan mangrove perairan Sungai Belawan (Kota Medan) merupakan daerah dimana hutan mangrovenya telah mengalami degradasi habitat serta konversi lahan; Stasiun 2 di Pantai Sialang Buah (Kabupaten Serdang Bedagai), merupakan wilayah pantai berpasir dimana diduga sebagai daerah pemijahan (spawning ground) belangkas, namun lokasi ini juga dalam 5 tahun terakhir telah mengalami abrasi; dan Stasiun 3 di Pantai Sungai Tawar (Kabupaten Labuhanbatu), merupakan wilayah dimana kondisi hutan mangrove masih sehat merupakan daerah mencari makan (feeding ground) belangkas. Berdasarkan informasi dari nelayan sekitar ketiga stasiun tersebut masih dapat jumpai belangkas.

Pengambilan sampel belangkas dilakukan menggunakan jaring insang ( ill net) yang ditebarkan sampai ke dasar perairan. Ada 3 jaring yang sama digunakan untuk tiap-tiap stasiun 
pengamatan (hal ini dianggap sebagai ulangan/plot). Namun pada lokasi yang tidak memungkinkan ditebar jaring insang dilakukan dengan metode ditangkap dengan tangan (hand sortir). Metode dan pengamatan kualitas air dapat dilihat pada Tabel 1.

Tabel 1. Metode dan Pengamatan Kualitas air

\begin{tabular}{|c|c|c|c|}
\hline No & $\begin{array}{c}\text { Parameter } \\
\text { yang diukur }\end{array}$ & Alat ukur & Metode \\
\hline 1 & Suhu & Termometer & Insitu \\
\hline 2 & Kecerahan & Secci disk & Insitu \\
\hline 3 & $\begin{array}{l}\text { Kecepatan } \\
\text { arus }\end{array}$ & $\begin{array}{l}\text { Stopwatch, } \\
\text { pelampung, } \\
\text { tali }\end{array}$ & Insitu \\
\hline 4 & $\mathrm{pH}$ & $\mathrm{pH}$ meter & Insitu \\
\hline 5 & $\begin{array}{l}\text { Disolved } \\
\text { Oxygen (DO) }\end{array}$ & DO meter & Insitu \\
\hline 6 & Salinitas & $\begin{array}{l}\text { Repracto- } \\
\text { Meter }\end{array}$ & Insitu \\
\hline 7 & Mercuri (Hg) & $\begin{array}{l}\text { Spectrophoto- } \\
\text { meter }\end{array}$ & Eksitu \\
\hline 8 & Timbal $(\mathrm{Pb})$ & $\begin{array}{l}\text { Spectrophoto- } \\
\text { meter }\end{array}$ & Eksitu \\
\hline 9 & $\begin{array}{l}\text { Kadmium } \\
(\mathrm{Cd})\end{array}$ & $\begin{array}{l}\text { Spectrophoto- } \\
\text { meter }\end{array}$ & Eksitu \\
\hline
\end{tabular}

Analisis data untuk menghitung densitas belangkas menggunakan Rumus:

$$
\mathrm{Ki}=\mathrm{Ni} / \mathrm{Na}
$$

Dimana: $\mathrm{Ki}=$ Kelimpahan; $\mathrm{Ni}=$ Jumlah individu hasil tangkapan; $\mathrm{Na}=$ Banyaknya angkatan.

Uji korelasi faktor fisika kimia air terhadap densitas belangkas menggunakan aplikasi program SPSS versi 22.

\section{HASIL DAN PEMBAHASAN \\ Suhu Air}

Berdasarkan hasil pengamatan rata rata suhu air yakni sebagai berikut: Pada stasiun $1\left(29^{\circ} \mathrm{C}\right)$, Stasiun $2\left(31^{\circ} \mathrm{C}\right)$, dan Stasiun $3\left(30^{\circ} \mathrm{C}\right)$. Terjadinya perbedaan suhu berdasarkan pengamatan diduga karena setiap lokasi pengamatan mempunyai karakteristik lingkungan yang berbeda. Menurut Khairul (2017) perbedaan suhu bisa terjadi dikarenakan beberapa hal di antaranya: perairan yang terbuka, badan sungai yang lebih lebar, dan keberadaan tumbuhan disekitarnya.

Selanjutnya dijelaskan oleh Salim $d k k$. (2017) suhu dengan kisaran yang berbeda bisa disebabkan oleh faktor perbedaan waktu pada saat pengamatan. Menurut Pratama $d k k$. (2015) distribusi suhu secara umum mengalami penurunan yang cukup signifikan pada periode musim Peralihan I (musim barat ke timur) hingga periode musim Peralihan II (musim timur ke barat). Suhu alami untuk perairan tropis yang layak untuk kehidupan organisme berkisar antara $23-32^{\circ} \mathrm{C}$ (Siburian $d k k$., 2017).

\section{Kecerahan Air}

Hasil pengamatan kecerahan air pada Stasiun 1 (93 centimeter), Stasiun 2 (75 centimeter) dan Stasiun $3 \quad$ (78 centimeter). Adanya perbedaan hasil pengamatan terhadap tingkat kecerahan air disebabkan oleh tingkat intensitas cahaya matahari yang menembus suatu perairan dan tingkat kekeruhan karena materi tersuspensi pada suatu perairan.

Hasil Penelitian Siburian $d k k$. (2017) menunjukkan kecerahan berkisar 0,5 meter sampai dengan 2 meter atau $25 \%$ sampai $100 \%$ (dalam skala batas kecerahan dibagi kedalaman). Kecerahan yang mencapai $100 \%$ umumnya pada kedalaman $<5$ meter, sedangkan perairan yang lebih dalam (>10 meter) tingkat kecerahannya lebih kecil yakni $<70 \%$ yang disebabkan oleh tingkat cahaya matahari yang menembus perairan. Kandungan padatan tersuspensi semakin tinggi menyebabkan semakin rendah tingkat kecerahan perairan. 


\section{Kecepatan Arus}

Pengamatan kecepatan arus ratarata pada Stasiun 1 (1,2 meter/detik), Stasiun 2 (1,1 meter/detik), dan Stasiun 3 (0,9 meter/detik). Arus di suatu perairan di pengaruhi beberapa faktor. Menurut Khairul (2017), arus air dipengaruhi oleh posisi perairan, pola arus dan massa air, pasang surut, dan pergerakan angin.

Kondisi oseanografi perairan yang meliputi arus dan karakteristik massa air merupakan daya dukung habitat biota laut (Puspitasari \& Suhartati, 2016).

\section{Derajat Keasaman (pH) Air}

Nilai pengukuran rata-rata derajat keasaman $(\mathrm{pH})$ pada Stasiun $1 \quad(6,5)$, Stasiun 2 (7,3), dan Stasiun $3(7,5)$. Perbedaan yang diperoleh tidak menunjukan nilai yang terlalu signifikan dan masih pada kondisi yang wajar. Tinggi rendahnya nilai $\mathrm{pH}$ di suatu perairan sangat dipengaruhi oleh kadar $\mathrm{CO}_{2}$ yang terlarut dalam perairan tersebut dan aktivitas fotosintesa merupakan proses yang sangat menentukan kadar $\mathrm{CO}_{2}$ dalam suatu perairan (Salim $d k k ., 2017$ ). pH sangat penting dalam menentukan nilai guna perairan untuk kehidupan organisme perairan. $\mathrm{pH}$ yang ideal untuk kehidupan biota akuatik adalah berkisar 6,5-8,5 (Siburian $d k k .$, 2017).

\section{Oksigen Terlarut (Disolved Oxygen)}

Disolved Oxygen (DO) berdasarkan stasiun pengamatan maka diperoleh nilai rata-rata pada Stasiun $1 \quad(5,1$ miligram/liter), Stasiun $2 \quad(5,3$ miligram/liter), dan Stasiun $3 \quad(6,2$ miligram/liter). Perbedaan nilai DO hampir sama dengan $\mathrm{pH}$, yakni tidak terlalu berbeda nyata dan masih dalam batas yang masih ditolerir.
Kondisi DO di suatu perairan dipengaruhi oleh proses respirasi biota air dan proses dekomposisi bahan organik oleh mikroba (Siburian $d k k$., 2017). Selanjutnya menurut Puspitasari \& Suhartati (2016) bergantung pada aktivitas fisik, biologi, dan biokimia dalam badan air. Kisaran tersebut secara umum menunjukkan nilai normal dan berada di atas baku mutu air laut untuk biota laut berdasarkan Kepmen LH No. 51 Tahun 2004, yaitu > 5 miligram/liter. Kondisi semua kadar DO pada tiap stasiun mendukung untuk kehidupan biota di laut.

Sebaliknya jika DO rendah, dapat diketahui bahwa air tersebut telah tercemar (Kementrian Lingkungan Hidup dan Kehutanan, 2015). DO merupakan variabel kimia yang mempunyai peranan yang sangat penting bagi kehidupan biota air sekaligus menjadi faktor pembatas bagi kehidupan biota (Siburian $d k k$., 2017).

\section{Salinitas}

Hasil pengukuran salinitas pada setiap stasiun berbeda. Pada Stasiun 1 ratarata salinitas berkisar (28 \%o), Stasiun 2 (30\%), dan Stasiun 3 (30\%). Rendahnya nilai salinitas pada Stasiun 1 (28 \%o) dikarenakan perairan Sungai Belawan merupakan perairan yang banyak dialiri sungai-sungai kecil dan besar, diantaranya Sungai Semayang, Sungai Terjun dan dekat dengan muara Sungai Deli. Hal ini tentunya menyebabkan salinitas di lokasi pengamatan menjadi rendah. Namun pada stasiun 2 dan 3 salinitas sama (30\%o), hal ini karena memang kondisi stasiun pengamatan tidak ada dialiri oleh sungaisungai besar di sekitarnya. Menurut Pratama $d k k$. (2015) distribusi salinitas menjadi sangat bervarias karena terjadi interaksi antara sistem angin muson dengan faktor-faktor yang lain, seperti run-off dari 
sungai, hujan, evaporasi, dan sirkulasi massa air.

\section{Merkuri (Hg)}

Hasil uji laboratorium terhadap kandungan $\mathrm{Hg}$ yang diambil dari sampel air dari masing-masing stasiun pengamatan, maka diperoleh nilai rerata pada Stasiun 1 (0,027 miligram/liter), Stasiun $2 \quad(0,005$ miligram/liter), dan Stasiun $3 \quad(0,004$ miligram/liter). Hasil analisis data pada Stasiun 1 menunjukan sudah tercemar berat sedangkan Stasiun 2 dan 3 tercemar ringan.

Menurut KepMen KLH No. 51 Tahun 2004 ambang batas $\mathrm{Hg}$ di perairan laut adalah 0,001 miligram/liter. Pada penelitian ini, hasilnya sangat jauh berbeda dengan yang pernah dilakukan oleh Wanna $d k k$. (2017) di kanal daerah Hertasning Kota Makassar yang menunjukan kadar merkuri (Hg) dengan nilai di bawah dari 0,0003 miligram/liter.

Di perairan alami logam berat $\mathrm{Hg}$ terdapat dalam bentuk $\mathrm{Hg}^{0}, \mathrm{Hg}^{+}$dan $\mathrm{Hg}^{2+}$ yang ditentukan oleh kondisi reduksi atau oksidasi. Perairan dimana terdapat oksigen terlarut cukup baik, maka $\mathrm{Hg}^{2+}$ terlarut menjadi dominan. Dalam keadaan reduksi atau fakultatif akan terbentuk $\mathrm{Hg}^{0}$ dan $\mathrm{Hg}^{+}$, dan apabila terdapat sulfit akan terbentuk senyawa $\mathrm{HgS}$. Di perairan yang tidak tercemar, kadar $\mathrm{Hg}^{2+}$ terlarut sekitar 0,020,1 miligram/liter (air tawar) dan $<0,01-$ 0,03 miligram/liter (air laut) (Sanusi, 2006).

\section{Timbal (Pb)}

Hasil pengamatan logam berat timbal $(\mathrm{Pb})$ rata-rata pada Stasiun $1(0,059$ miligram/liter $), \quad$ Stasiun $2 \quad(0,023$ miligram/liter), dan pada Stasiun 3 (0,019 miligram/liter). Secara umum perbedaan konsentrasi $\mathrm{Pb}$ di tiap stasiun disebabkan oleh berbagai proses fisika, biologi, dan kimia di perairan.

Menurut KepMen KLH No. 51 Tahun 2004 ambang batas $\mathrm{Pb}$ di perairan laut adalah 0,008 miligram/liter. Menurut Indirawati (2017), $\mathrm{Pb}$ dihasilkan oleh limbah industri yang berada di sekitar lokasi penelitian, $\mathrm{Pb}$ juga berasal dari transportasi laut yaitu kapal nelayan yang menggunakan bahan bakar bensin. $\mathrm{Pb}$ banyak digunakan pada industri baterai, kabel, penyepuhan, pestisida, sebagai zat anti letup pada bensin, zat penyusun patri atau solder, sebagai formulasi penyambung pipa.

Tingginya $\mathrm{Pb}$ pada Stasiun 1 karena muara Sungai Belawan berdekatan dengan Muara Sungai Deli, dimana pada aliran Sungai Deli bagian atasnya banyak Industi Besi dan Baja, selain itu adanya perusahaan Penggalangan kapal di Belawan. Nilai logam $\mathrm{Pb}$ di perairan Sungai Belawan sudah melebihi ambang baku mutu. Nilai baku mutu kandungan $\mathrm{Pb}$ di perairan yang dipersyaratkan menurut Kepmen LH No. 51 Tahun 2004, yaitu 0,05 mg/l. Suharto (2005) menyatakan bahwa pencemaran $\mathrm{Pb}$ di perairan yang melebihi konsentrasi ambang batas dapat menyebabkan kematian bagi biota perairan.

\section{Cadmium (Cd)}

Hasil pengamatan logam berat Cadmium (Cd) rata-rata pada Stasiun 1 (0,061 miligram/liter), Stasiun $2(0,025$ miligram/liter), dan pada Stasiun 3 (0,015 miligram/liter). Pencemaran logam Cd pada Stasiun 1 cukup tinggi dan melebihi ambang batas pada baku mutu berdasarkan KepMen KLH No. 51 Tahun 2004 yakni, 0,05 miligram/liter.

Cd yang ada di perairan berasal dari berbagai proses yaitu $\mathrm{Cd}$ masuk ke dalam perairan karena adanya proses erosi tanah, 
pelapukan batuan induk. Cd lebih banyak masuk ke dalam air karena kegiatan manusia seperti perindustrian dimana limbah hasil dari pabrik tersebut dibuang langsung ke dalam perairan yang akan terakumulasi di dasar perairan yang membentuk sedimen. Hasil penelitian Indirawati (2017) menunjukan rerata $\mathrm{Cd}$ di perairan Sungai Belawan adalah 0.056 miligram/liter. Ambang batas logam berat $\mathrm{Cd}$ untuk kehidupan organisme laut adalah 0,001 part per million (ppm) (Setiawan \& Endro, 2015).

\section{Densitas Belangkas}

Hasil tangkapan belangkas pada Stasiun 1 sebanyak 3 ekor, Stasiun 2 sebanyak 4 ekor dan pada stasiun 3 sebanyak 12 ekor. Berdasarkan hasil analisis densitas belangkas, maka Stasiun 3 merupaka mempunyai densitas tertinggi, diikuti stasiun 2 dan 3.

Data hasil analisis densitas rerata hasil tangkapan belangkas selengkapnya dapat dilihat pada Tabel 2.

Tabel 2. Densitas Belangkas pada Setiap Stasiun Pengamatan

\begin{tabular}{lccc}
\hline & \multicolumn{3}{c}{ Hasil Tangkapan } \\
\cline { 2 - 4 } & Stasiun 1 & Stasiun 2 & Stasiun 3 \\
\hline Rerata & 1 & 1,33 & 4 \\
\hline
\end{tabular}

Tingginya densitas belangkas yang terdapat pada Stasiun 3 diduga karena kondisi hutan mangrove pada daerah ini masih baik. Menurut Anggraini $d k k$. (2017); Chen dkk. (2015), ekosistem mangrove menjadi daerah mencari makan (feeding groud) yang baik bagi belangkas, karena menyediakan berbagai sumber makanan.

\section{Korelasi Faktor Fisika Kimia Terhadap Densitas Belangkas}

Korelasi kondisi faktor fisika kimia terhadap densitas belangkas di Pantai Timur Sumatera Utara dilakukan dengan uji korelasi bivariat menggunakan aplikasi SPSS Versi 22. Hasil analisis dapat dilihat pada Tabel 3.

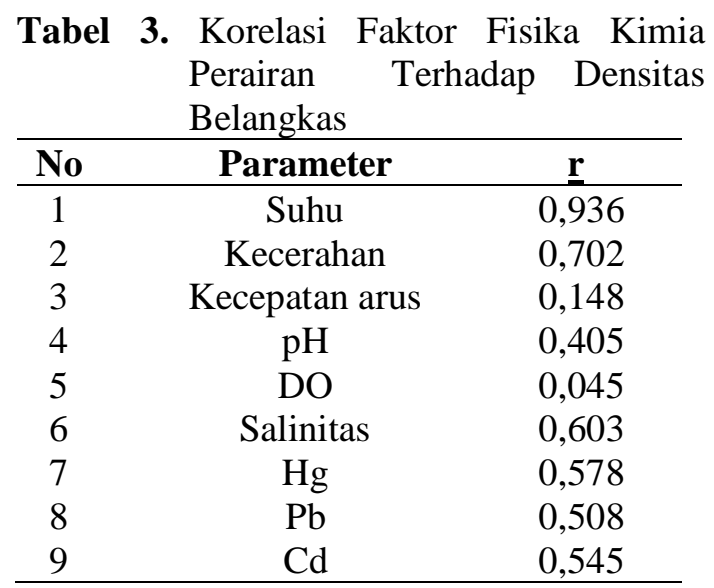

Keterangan: (+) Arah Korelasi Searah

Berdasarkan hasil analisis korelasi parameter faktor fisika kimia perairan terhadap densitas belangkas menunjukan hubungan korelasi searah (+). Menurut Rosmaniar (2008) korelasi searah (+) menunjukan terjadinya hubungan yang searah antara nilai kepadatan populasi, artinya semakin tinggi nilai fisika kimia perairan maka nilai kepadatan populasi semakin tinggi.

Kondisi faktor fisika kimia perairan seperti: suhu, kecerahan, kecepatan arus, $\mathrm{pH}$, DO dan salinitas tentunya merupakan kebutuhan untuk kehidupan belangkas karena merupakan faktor pembatas.

Namun hal ini tidak berlaku untuk logam berat seperti: $\mathrm{Hg}, \mathrm{Pb}$, dan $\mathrm{Cd}$, dikarenakan bila kondisinya diambang batas akan bersifat toksit (racun) bagi belangkas. Menurut pendapat Yudo (2006) pemantauan kadar logam berat seperti: $\mathrm{Hg}$, $\mathrm{Cd}, \mathrm{Pb}$, dan $\mathrm{Cr}$ perlu dilakukan karena 
dapat bersifat racun di perairan.

Nilai korelasi tertinggi yakni pada suhu (0,936). Suhu memiliki hasil yang secara signifikan berpengaruh terhadap kelimpahan belangkas. Suhu perairan merupakan faktor pembatas (limiting factor) bagi hewan Crustacea dan salah satunya adalah belangkas.

Meynecke \& Richards (2013) menjelaskan pada penangkapan jenis Crustcea lainya (Scylla serrata) dapat berbeda dari musim ke musim dan penyebab fluktuasi bisa dipengaruhi kondisi faktor lingkungan penentu seperti: suhu air, salinitas, nutrisi, sedimentasi, masuknya bahan pencemar, predator, dan upaya penangkapan.

\section{KESIMPULAN DAN SARAN}

Kesimpulan dari hasil analisis korelasi faktor fisika kimia perairan terhadap densitas belangkas menunjukan nilai korelasi searah (+). Selanjutnya berdasarkan hasil pengujian sampel air dapat diketahui kondisi perairan Sungai Belawan sudah tercemar logam berat, terutama unsur $\mathrm{Hg}$, $\mathrm{Cd}$, dan $\mathrm{Pb}$.Disarankan bagi peneliti selanjutnya untuk melakukan pengukuran kondisi faktor fisika kimia perairan pada setiap hari, hal ini untuk memperoleh data parameter fisika dan kimia perairan secara lebih lengkap dan akurat.

\section{UCAPAN TERIMA KASIH}

Pada kesempatan ini penulis mengucapkan terima kasih kepada Direktorat Riset dan Pengabdian Kepada Masyarakat (DPRM) Kemenristek Dikti yang telah membantu dana penelitian untuk skema Penelitian Dosen Pemula (PDP).

\section{DAFTAR RUJUKAN}

Anggraini, R., Dietriech G. Bengen, \& Natih, N, M. N. (2017). Struktur Populasi Dan Morfometri Belangkas Carcinoscorpius rotundicauda, Latreille 1802 Di Pesisir Kampung Gisi Teluk Bintan Kepulauan Riau. Jurnal Ilmu dan Teknologi Kelautan Tropis, 9 (1), 211-220.

Cartwright-Taylor, L., Bing, Y. V., Chi, H. C., \& Tee, L. S. (2011). Distribution and abundance of horseshoe crab Tachypleus gigas and Carcinoscorpius rotundicauda around the main island Singapore. Aquatic Biology, 13, 127-136.

Chen, Chang-Po, Yang, Ming-Che, Fan, LanFeng, Qiu, G., Liao, Yong-Yan, \& Hsieh, Hwey-Lian. (2015). Cooccurrence of juvenile horseshoe crabs Tachypleus tridentatus and Carcinoscorpius rotundicauda in an estuarine bay, southwestern China. Aquatic Biology, 24, 117-126.

Fan, Lan-Feng, Chen, Chang-Po, Yang, Ming-Che, Qiu, G., Liao, Yong-Yan \&Hsieh, Hwey-Lian. (2017). Ontogenetic Changes in Dietary Carbon Sources and Trophic Position of Two Co-Occurring Horseshoe Crab Species In Southwestern China. Aquatic Biology, 26, 15-26.

Indirawati, S. M. (2017). Pencemaran Logam Berat $\mathrm{Pb}$ dan $\mathrm{Cd}$ dan Keluhan Kesehatan Pada Masyarakat Di Kawasan Pesisir Belawan. Jurnal Jumantik, 2(2), 54-60.

Kementerian Lingkungan Hidup Republik Indonesia. (2004). Keputusan Menteri Negara Lingkungan Hidup No. 51 Tahun 2004 tentang Baku Mutu Air Laut. Himpunan Peraturan di Bidang Pengelolaan Lingkungan Hidup dan Penegakan Hukum Lingkungan. Pada: http://www.ppk-

kp3k.kkp.go.id/ver3/media/download/R E_keputusan-menteri-negara- 
lingkungan-hidup-nomor-51-tahun2004_20141008143942.pdf. Diakses tanggal 25 Januari 2019.

Kementrian Lingkungan Hidup dan Kehutanan. (2015). Inventarisasi Sumber Pencemar Lingkungan Pesisir dan Laut yang Berasal dari Non Point Sourches di Tanjung Benoa. Pada: http://perpustakaan.bappenas.go.id/lont ar/file?file=digital/166949-[_Konten_]Konten\%20D1876.pdf. Diakses tanggal 25 Desember 2018.

Khairul. (2017). Studi Faktor Fisika Kimia Perairan Terhadap Biota Akuatik Di Ekosistem Sungai Belawan. Prosiding Seminar Nasional Multidisiplin Ilmu UNA, Kisaran. Hal: 1132-1140.

Mashar, A., Butet, N. A., Juliandi, B., Qonita, Y., Hakim, A. A., \& Wardiatno, Y. (2017). Biodiversity and Distribution of Horseshoe Crabs in NorthernCoast of Java and Southern Coast of Madura. IOP Conf. Series: Earth and Environmental Science, 54 (2017) 012076.

Meilana, L. (2015). Kajian Morfologi dan Genetik Mimi (Xiphosura, Limulidae) Sebagai Dasar Konsevasi dan Pengelolaan Di Pulau Jawa. Tesis Sekolah Pasca Sarjana Institut Pertanian Bogor, Bogor.

Meynecke, J. O. \& Richards, R. G. (2013). A Full Life an Sptially Explicit Individual Based Model For The Giant Mud Crab (Scylla serrrata): A Case Study From A Marine Protect Area. ICES Journal of Marine Science, 13, 1-15.

Mulya, M. B. (2004). Pelestarian, Pemanfaatan Sumberdaya Genetik Mimi Ranti (Carcinosscorpius rotundicauda, L) dan Mimi Bulan (Tachypleus gigas, M). (C) 2004 Digitized by USU digital library.

Peraturan Pemerintah Republik Indonesia Nomor 7 Tahun 1999. Tentang Pengawetan Jenis Tumbuhan dan Satwa.
Pratama, G. A., Pranowo, W. S., Sunarto, \& Purba, N. P. (2015). Keterkaitan Kondisi Parameter Fisika Dan Kimia Perairan Dengan Distribusi Klorofil-A Di Perairan Barat Sumatera. Omni Akuatika, XIV (20), 33-43.

Puspitasari, R., \& Suhartati, M. N. (2016). Kualitas Lingkungan Untuk Menunjang Budidaya Biota Laut Di Perairan Lombok Barat. LIPI Press, Jakarta. 224 Hal.

Razali, M. M. R. \& Zaleha, K. (2017). Fishery Aspect of Horseshoe Crab [Tachypleus gigas (Müller, 1785)] in the Peninsular Malaysia: Exploitation Status. Universal Journal of Applied Science, 5(2), 11-15.

Rosmaniar. (2008). Kepadatan dan Distribusi Kepiting Bakau (Scylla spp) Serta Hubungannya Dengan Faktor Fisika Kimia Di Perairan Pantai Labu Kabupaten Deli Serdang. Tesis Jurusan Biologi Fakultas Matematika dan Ilmu Pengetahuan Alam, Universitas Sumatera Utara, Medan. 78 halaman.

Salim, D., Yuliyanto, \& Baharuddin. (2017). Karakteristik Parameter Oseanografi Fisika-Kimia Perairan Pulau Kerumputan Kabupaten Kotabaru Kalimantan Selatan. Jurnal Enggano, 2(2), 218-228

Sanusi, H. S. (2006). Kimia Laut Proses Fisik Kimia dan Interaksinya dengan Lingkungan. Karya Ilmiah Departemen Ilmu dan Teknologi Kelautan, Fakultas Perikanan dan Ilmu Kelautan Institut Pertanian Bogor, Bogor.

Setiawan, H., \& Endro, S. (2015). Konsentrasi Logam Berat Pada Air dan Sedimen Di Perairan Pesisir Provinsi Sulawesi Selatan. Indonesian Forest 
Rehabilitation Journal, 3 (1), 67-79.

Siburian, R., Lisnawaty, S., \& Minsyahril, B. (2017). Analisis Kualitas Perairan Laut Terhadap Aktivitas Di Lingkungan Pelabuhan WaingapuAlor Sumba Timur. Jurnal Pengabdian Kepada Masyarakat, 23 (1), 225-232.

Smith, D. R., Beekey, M. A., Brockmann, H. J., King, T. L., Millard, M. J. \& Zaldívar-Rae, J. A. (2016). Limulus polyphemus. The IUCN Red List of Threatened Species 2016: e.T11987A80159830. http://dx.doi.org/10.2305/IUCN.UK.2 016-1.RLTS.T11987A80159830.en. Downloaded on 30 September 2018.

Suharto. (2005). Dampak Pencemaran Logam Timbal $(\mathrm{Pb})$ Terhadap Kesehatan Masyarakat. Majalah Kesehatan Indonesia No. 165. Universitas Airlangga. Surabaya.

Taylor, L. C., Lee, J., \& Hsu, C. C. (2011). Population Structure and Breeding Pattern of The Mangrove Horseshoe Crab Carcinoscorpius rotundicauda In Singapore. Aquatic Biology, 8, 6169.

Ubaidillah, R., Marwoto, R. M., Hadiyaty, R. K., Fahmi, Wowor, D., Mumpuni, Pratiwi, R., Tjakrawidjaja, A. H., Mudjiyono, Hartati, S. T., Heryanto, Riyanto, A., \& Mujiono, N. (2013). Biota Perairan Terancam Punah Di Indonesia Prioritas Perlindungan. Direktorat Konservasi Kawasan dan Jenis Ikan Ditjen Kelautan, Pesisir, dan Pulau-Pulau Kecil. Kementerian Kelautan dan Perikanan. Jakarta. 198 halaman.

Wanna, M., Subari, Y., \& Kadirman. (2017). Analisis Kualitas Air Dan Cemaran Logam Berat Merkuri ( $\mathrm{Hg})$ dan
Timbal $(\mathrm{Pb})$ Pada Ikan Di Kanal Daerah Hertasning Kota Makassar. Jurnal Pendidikan Teknologi Pertanian, 3, 197-210.

Yudo, S. (2006). Kondisi Pencemaran Logam Berat Di Perairan Sungai DKI Jakarta. JAI, 2(1), 1-15.

Yusuf, M. (2017). Metode Penelitian (Kuantitatif, Kualitatif, \& Penelitian Gabungan). Kencana, Jakarta. 